\title{
NOTAS SOBRE FRACASSO E DIVERSIDADE: OS SENTIDOS DO APRENDER E DO NÃO APRENDER NA ESCOLA
}

\section{NOTAS SOBRE FRACASO Y DIVERSIDAD: LOS SENTIDOS DEL APRENDER Y DEL NO APRENDER EN LA ESCUELA}

\author{
NOTES ON FAILURE AND DIVERSITY: MEANINGS OF LEARNING AND NOT \\ LEARNING IN SCHOOLS
}

\author{
Maria Letícia Cautela de Almeida MACHADO ${ }^{1}$ \\ Paula da Silva Vidal Cid LOPES ${ }^{2}$ \\ Luiz Antonio Gomes SENNA ${ }^{3}$
}

RESUMO: Este artigo é resultado de estudos produzidos pelo Núcleo de Linguagens, Alfabetização e Letramento da UERJ, no contexto do Grupo de Pesquisa Linguagem, Cognição Humana e Processos Educacionais. Em formato de relato de pesquisa de base teóricoconceitual, tem-se como objetivo apresentar uma discussão que contribua para o debate acerca das proposições teóricas que, embora se apresentem como um olhar interdisciplinar da Educação, acabam por supervalorizar uma perspectiva clínica e biológica da aprendizagem em contexto escolar, a despeito de ser esta marcada por diversidades em diferentes formas. Defende-se aqui que o olhar interdisciplinar direcionado aos sentidos da aprendizagem e da não aprendizagem deve dar relevo à questão da diversidade cultural e sua relação com os processos de superação e inclusão no âmbito escolar. O estudo encontra-se dividido em três partes: análise crítica das assim chamadas teorias biologizantes do fracasso escolar, com ênfase no papel que desempenham no processo de estigmatização do sujeito escolar; análise do papel dos estudos culturais para o avanço na compreensão do fracasso escolar, e; descrição conceitual das noções discursivas que contribuem para a compreensão dos processos de construção de conhecimento sob a perspectiva da diversidade cultural.

PALAVRAS-CHAVE: Ensino-aprendizagem. Fracasso escolar. Diversidade cultural. Discurso.

RESUMEN: Este artículo resulta de estudios producidos en el Núcleo de Lenguajes, Alfabetización y Letramento de la UERJ, en el ámbito del Grupo de Investigación Lenguaje, Cognición Humana y Procesos Educacionales. En forma de relato de investigación de basis

\footnotetext{
${ }^{1}$ Universidade do Estado do Rio de Janeiro (UERJ), Rio de Janeiro - RJ - Brasil. Professora Adjunta no Departamento de Estudos Aplicados ao Ensino. Doutorado em Educação (UERJ). ORCID: https://orcid.org/00000002-9500-1625. E-mail: maria leticia2005@hotmail.com

${ }^{2}$ Universidade do Estado do Rio de Janeiro (UERJ), Rio de Janeiro - RJ - Brasil. Professora Associada no Departamento de Estudos Aplicados ao Ensino. Doutorado em Educação (UERJ). ORCID: https://orcid.org/00000002-2170-0546. E-mail: paulacidlopes@gmail.com

${ }^{3}$ Universidade do Estado do Rio de Janeiro (UERJ), Rio de Janeiro - RJ - Brasil. Professor Titular no Programa de Pós-Graduação em Educação e no Departamento de Estudos Aplicados ao Ensino. Doutorado em Linguística Aplicada (PUC-Rio). Pesquisador bolsista dos programas PROCIENCIA (UERJ/FAPERJ) e CNE da Fundação FAPERJ. Bolsista de produtividade acadêmica da Fundação CECIERJ. ORCID: https://orcid.org/0000-00021086-8829. E-mail: senna@uerj.br
} 
teórico-conceptual, se tiene acá por objetivo presentar una discusión que contribuya en el debate de las teorías que, aunque se presenten como aportes interdisciplinarios para la Educación, concentran-se en una perspectiva clínica y biológica del aprendizaje escolar, a pesar de que esta sea caracterizada por diferentes formas de diversidad. Defiende-se que el ojear interdisciplinario direccionado a los sentidos del aprendizaje y no aprendizaje debe poner en relevo la diversidad cultural, así como su relación con los procesos de superación e inclusión en ámbito escolar. El estudio encuentra-se dividido en tres partes: análisis crítico de las teorías del fracaso escolar conocidas como biologizantes, con énfasis en su papel en el desarrollo del proceso de estigmatización del sujeto escolar; análisis del role de los estudios culturales para el avance en la comprensión del fracaso escolar, y; descripción conceptual de nociones discursivas que contribuyen para la comprensión de los procesos de construcción de conocimiento bajo la perspectiva de la diversidad cultural.

PALABRAS-CLAVE: Enseñanza-aprendizaje. Fracaso escolar. Diversidad cultural. Discurso.

ABSTRACT: This paper results from studies held on UERJ's nucleus Linguagem, Alfabetização e Letramento, held by research group Language, Human Cognition and Educational Processes. Based on a theoretic survey, it presents a contribution to debate concerning such theories that, even though presented as interdisciplinary approaches for Education, tend to overvalue a clinic most biological perspective of scholar learning, spite of being schools intrinsically associated to different forms of diversity. Herein it's defended that interdisciplinary approaches oriented to Education must highlight cultural diversity and it's role on school processes of overcoming and inclusion. Survey is presented in three parts: critical analysis of so called biological theories of school failure, with emphasis on their role on the stigmatization of school subjects; analysis of the contribution of cultural studies to the advance of comprehension about school failure, and; description of discursive notions that impact to the comprehension of knowledge construction under the perspective of cultural diversity.

KEYWORDS: Teaching-learning. School failure. Cultural diversity. Discourse.

\section{Introdução}

$\mathrm{O}$ artigo que aqui se apresenta é resultado de estudos produzidos pelo Núcleo de Linguagens, Alfabetização e Letramento, no contexto do Grupo de Pesquisa Linguagem, Cognição Humana e Processos Educacionais, ambos alocados na Faculdade de Educação/Campus Maracanã, da Universidade do Estado do Rio de Janeiro. Ao longo de mais de vinte anos, este Grupo de Pesquisa investe esforços em formação acadêmica, nos níveis da graduação e da pós-graduação, que alicerce os princípios democráticos e inclusivos da escola pública à produção científica e qualificada na área da alfabetização e da formação de leitores e escritores crianças, jovens e adultos. 
Em formato de relato de pesquisa de base teórico-conceitual, tem-se como objetivo apresentar uma discussão que contribua para o debate acerca das proposições teóricas que, embora preconizem um olhar interdisciplinar na Educação, acabam por supervalorizar uma perspectiva clínica e biológica da aprendizagem em contexto escolar, sendo esta, entretanto, marcada por diversidades em diferentes formas. O olhar interdisciplinar direcionado aos sentidos da aprendizagem e da não aprendizagem precisam, entretanto, partir e chegar ao ponto convergente das superações e dos processos de inclusão social: a diversidade cultural.

Tudo o que se vive na escola é parte dos processos de inclusão social, porque, para além de conteúdos, métodos e fórmulas, a escola se reveste hoje de outras urgências, marcando-se como espaço de resistência e legitimidade de direitos. É possível exemplificar esta urgência quando verificamos mudanças que são impostas à escola e à formação de professores ao se mudar o perfil político da gestão pública.

No contexto atual da Educação no Brasil, podemos citar como exemplo a Política Nacional de Alfabetização (BRASIL, 2019a) e a recente Base Nacional Comum de Formação Inicial de Professores da Educação Básica (BRASIL, 2019b). Tais documentos apregoam o respaldo em "teorias cientificamente comprovadas", tidas como verdades absolutas e passíveis de generalização para que se tenha modelos de estudantes, bem como modelos de professores a serem imitados.

Quando se faz a opção por modelos de aprendizagem, é comum a aderência a teorias de caráter generalista que expliquem a não aprendizagem na falsa ideia de que processos complexos como a aprendizagem possam ser elucidados facilmente, por uma única lente para a leitura dos fenômenos, o que acaba por motivar perspectivas medicamentosas e supostamente salvadoras para a não aprendizagem.

Assumindo a escola como este espaço de aprendizagens transdisciplinares, conforme sonha Japiassu (2006), conferimos aos estudos histórico-culturais o referencial privilegiado na elaboração das argumentações que aqui se constroem e que refutam a visão biologizante de processos tão múltiplos como são os da aprendizagem humana.

A construção desta perspectiva, neste artigo, se dá por três vias congruentes: a) Teorias biologizantes e a perpetuação de estigmas da não aprendizagem; b) Estudos histórico-culturais e a superação da noção de sujeito do fracasso escolar; c) A interdiscursividade como via para a produção de sentidos na aprendizagem escolar. 


\section{Teorias biologizantes e a perpetuação de estigmas da não aprendizagem}

Ao longo das últimas décadas, temos acompanhado, no Brasil, um número crescente de alunos que, por não corresponderem às expectativas da escola com relação à aprendizagem e ao domínio da língua escrita têm sido encaminhados às unidades de saúde para atendimento especializado. Segundo Garcia (2004), esse movimento tem tomado tal proporção que o problema começa a ser entendido como uma questão de saúde pública.

Esses encaminhamentos são realizados por professores e ratificados por grupos de profissionais que atuam nos campos da Educação e da Saúde, os quais, de um modo geral, tomam modos de escrita e leitura não convencionais como sintomáticos e atribuem suas causas a deficiências inerentes ao sujeito. Dessa forma, alunos que não aprendem o que e como a escola se propõe a ensinar são previamente rotulados como portadores de algum distúrbio ou disfunção. O sujeito desviante, ou imaturo, surge, desse modo, como efeito do discurso pedagógico e médico e de seus dispositivos de normalização.

Tais dispositivos são decorrentes de um processo de medicalização da Educação, que, por sua vez, insere-se num mecanismo mais amplo de medicalização da vida e da sociedade, iniciado há quase dois séculos. Moysés (2008) afirma que tal processo transforma fenômenos humanos e sociais, historicamente construídos, em questões individuais, de modo que o que escapa à norma, o que foge à regra, o que não funciona como estabelecido, é transformado em doença, em problema biológico individual.

Moysés e Collares (2013) explicam que a medicina constituiu seu estatuto de ciência moderna, na transição entre os séculos XVIII e XIX, atribuindo-se a competência para legislar e normatizar o que vem a ser saúde ou doença - o que significa definir o homem modelo. Desse modo, adotando um discurso cientificista genérico, aplicável a todas as pessoas, porque neutro, a medicina apoia-se na invariância da determinação biológica do homem para estabelecer o que é normal e o que é patológico.

É necessário salientar que o campo de normatividade da medicina se estende para o ambiente escolar, justamente nessa passagem de século, quando as transformações políticas e econômicas decorrentes do capitalismo demandam novas formas de organização da sociedade e de ocupação dos espaços, surgindo com as cidades novos problemas, destacando-se, desde o início, as doenças. Neste contexto, como assinala Moysés (2008), a medicina, afinada com as demandas dos grupos hegemônicos, atribui a doença à ignorância da população e elege a escola como um lugar privilegiado para combatê-la. Nessa maneira de conceber o processo saúdedoença não há espaço para determinantes sociopolíticos, como condições de vida precárias, 
desigualdade de oportunidades ou ausência de políticas públicas, isentando-se de responsabilidades todas as instâncias de poder.

Foi assim que surgiu o movimento de Puericultura e o Serviço de Saúde Escolar (originalmente designado de Higiene Escolar) que, segundo o próprio entendimento, tinha o objetivo de romper com a ignorância dos pais, responsáveis pela falta de hábitos de higienização, e garantir condições de saúde adequadas à aprendizagem. Respaldada por esses pretensos objetivos, a medicina passou a normatizar e legislar sobre questões educacionais que englobavam desde os padrões de construção dos prédios escolares, a dimensão de corredores, a altura de degraus, os móveis escolares e sua distribuição espacial; até mesmo o currículo, o que o aluno devia ou não aprender, as horas de trabalho e de recreio; e, por fim, os modos de se comportar, ensinar e aprender na escola (MOYSÉS, 2008).

Patto (2008) sinaliza que o discurso higienista da saúde escolar era impregnado pelas ideias racistas e do eugenismo, havendo uma afinidade com a ideologia dominante. Antes mesmo que a efetiva democratização do ensino no Brasil possibilitasse aos filhos da classe trabalhadora o acesso à escola, a medicina já alertava, a priori, que eram crianças pobres debilitadas, desnutridas, doentes, malcuidadas e, portanto, iriam apresentar problemas para aprenderem, a menos que houvesse uma intervenção médica. Deste modo, o preconceito (social, racial, de gênero, e até linguístico) foi cientificizado, maquiado por teorias genéticas e sociológicas, aparentadas ao reducionismo biológico e ao darwinismo social. A autora assinala que:

A visão preconceituosa, de profundas raízes sociais, encontra apoio nos resultados de pesquisas que fundamentam as afirmações de uma ciência que, tendo como álibi uma pretensa objetividade e neutralidade, eleva uma visão ideológica de mundo à categoria de saber (PATTO, 2008, p. 420).

Sobre tal problemática, Hobsbawm (1982), já declarava que nunca mais iria ser tão fácil para o senso comum mobilizar o universo para confirmar seus próprios preconceitos. Para o autor, o darwinismo social e a antropologia racista pertencem não à ciência do século XIX, mas a sua política.

Deste modo, sob a pretensa cientificidade, aplicou-se à escola, ao aluno e ao objeto de aprendizagem escolar as concepções que embasam o determinismo biológico, tudo sendo reduzido ao mundo da natureza, autorizando que os processos de ensino e de aprendizagem passassem a ser analisados por meio de critérios perpassados pela ciência positivista e pelo pensamento naturalista. Assim, como assinala Moysés (2008), o sujeito passou a ser visto apenas como corpo biológico - não o seu corpo, mas um corpo genérico, abstrato e universal - 
e a aprendizagem tornou-se um dos elementos constitutivos dessa entidade, adquirindo as mesmas características. Ou seja, transformada em elemento de um corpo biológico, também a aprendizagem e, principalmente, a não-aprendizagem, foi tomada em processo de abstração para que o olhar clínico pudesse se efetivar com toda a sua racionalidade e objetividade.

A partir disto, o diagnóstico de questões que não se inscreviam no campo da medicina foi incorporado ao ato médico, sem conflitos. Aprendizagem, comportamento, linguagem, inteligência são apenas exemplos de questões que foram incorporadas ao pensamento e atuação médicos. E assim,

Da proposição inicial de normatizar, legislar e vigiar o cumprimento das normas preconizadas para garantia da saúde e da aprendizagem saudável, um rápido giro do olhar possibilitará a criação das doenças da aprendizagem, ou melhor, as doenças do não-aprender (MOYSÉS, 2008, p. 4).

Por conseguinte, a partir do aumento da demanda por serviços de saúde especializados na resolução dessas doenças do não aprender, instituiu-se o campo médico-pedagógico. Com este, criou-se um corpo de especialistas, definiu-se sistemas classificatórios e instaurou-se um paradigma teórico médico positivista que sustentaria tanto a formação dos especialistas quanto a atuação frente a essas doenças, persistindo de forma hegemônica até a atualidade.

Assim, ao medicalizar a educação, transformou-se (e ainda se transforma) problemáticas sócio-políticas, pedagógicas, institucionais, linguísticas ou afetivas em questões biológicas, estritamente individuais. A partir de então, iniciou-se a construção artificial de entidades nosológicas para explicar o não aprender na escola. MOYSÉS (2008, p. 11) revela que:

Sem qualquer fundamentação, empírica ou teórica, indo mesmo contra todas as evidências em contrário constantemente colocadas pela realidade, constituiu-se uma espiral viciada, em que, a partir de um olhar balizado por uma crença, deforma-se a realidade e a realidade deformada passa a ser apresentada como a comprovação empírica da crença.

E assim, ao longo de mais de um século, desde 1896 quando surgiu na Inglaterra a primeira especulação sobre a doença que impediria a criança de aprender - a cegueira verbal congênita -, "vem sucedendo-se as explicações e os nomes, sempre sem comprovação; a cada crítica, transforma-se em uma entidade, com explicações fisiopatológicas mais sofisticadas, omitindo-se a ausência de alicerces científicos” (MOYSÉS, 2008, p. 11). A cegueira verbal congênita cedeu lugar para a strephosymbolia, que, por sua vez, virou dislexia específica de evolução e, por fim, dislexia de desenvolvimento; por outro lado, a lesão cerebral mínima foi substituída pela disfunção cerebral mínima, que deu lugar ao distúrbio por déficit de atenção, 
que, mais recentemente, cedeu espaço ao transtorno do déficit de atenção e hiperatividade (TDAH).

Especificamente com relação à aprendizagem da língua escrita, diversas nomenclaturas têm sido utilizadas para se referir às dificuldades apresentadas pelos alunos: distúrbio de aprendizagem, dislexia, disortografia, discalculia, disgrafia, entre outras. Porém, independente da nomenclatura usada, o problema, ordinariamente, é localizado no organismo do sujeito, obscurecendo toda uma série de aspectos que pode interferir de maneira contraproducente no processo de aprendizagem.

Isso ocorre porque as explicações causais para as dificuldades de leitura e escrita foram desenvolvidas pela área de saúde, distante do contexto escolar, pautadas em estudos afasiológicos. A partir disto, uma patologia chamada dislexia adquirida, relacionada a sujeitos adultos vítimas de lesões cerebrais, parece ter servido de apoio para determinar uma visão equivocada que toma fatos linguísticos associados ao processo de aprendizagem e uso da língua escrita como sinais de uma doença.

Machado e Signor (2014) explicam que, pautada em um raciocínio clínico tradicional, o qual parte do princípio de que se X causa $\mathrm{Y}$, Y só pode ser causado por X, a medicina supôs que se uma lesão cerebral, em sujeitos adultos, poderia ocasionar dificuldades para ler e escrever, então dificuldades apresentadas por crianças que estão em processo de alfabetização deveriam ser causadas por danos neurológicos. A partir desse raciocínio, crianças que não aprendiam a ler e escrever como a escola gostaria passaram a ser diagnosticadas como portadoras de dislexia. E assim, as dificuldades na aprendizagem da língua escrita começaram a ser explicadas a partir de uma abordagem organicista, associando explicações neurológicas, genéticas, anatômicas, metabólicas ou funcionais a tais quadros.

Contudo, Moysés (2010) afirma que não existe embasamento científico que comprove, de fato, a existência dessa doença. A autora demonstra, a partir de uma análise científica, que não há qualquer comprovação de alterações anatômicas no cérebro e argumenta que não há elementos precisos para esse diagnóstico, tampouco critérios mínimos de objetividade. E defende com veemência tal posicionamento:

Preconiza-se que exista uma doença neurológica que comprometeria só a linguagem escrita e o diagnóstico é feito usando só a linguagem escrita. Desculpem, mas isso não é um diagnóstico, no sentido médico, isso é um processo de rotulação, em que a criança desaparece no processo; a criança e o adolescente deixam de ser um sujeito, com toda a complexidade que o constitui, e se tornam apenas um doente. De uma doença jamais comprovada! (MOYSÉS, 2010, p. 14). 
Machado e Signor (2014), acrescentam que, além disso, correlacionar, tal como vêm sendo feito em grande parte dos estudos nas neurociências, modelos particulares de funcionamento neurofisiológico do cérebro com o que tem sido considerado desvios da escrita não é argumento suficiente para que se possam explicar fatos linguísticos em termos neurofisiológicos. Isso porque, para que o exame de neuroimagem detecte a atividade na área de leitura, essa precisa ser ativada e para isso usa-se tarefas com a própria linguagem escrita, de modo que se o sujeito não a domina, o exame, em si, não tem razão de ser, como bem explica Moysés (2010):

Um pesquisador americano fez o seguinte: ele aplicou o Pet em americanos bons leitores dando a eles um texto em inglês para lerem; o resultado do Pet foi normal. Depois, repetiu o exame dando um texto em espanhol, que eles não conheciam e o resultado do Pet foi "de dislexia". E aí? O que o exame avalia? Ele avalia a atividade cerebral na área da leitura quando eu sei ler um texto que me dão. Se não tenho domínio da linguagem escrita, o exame perde o significado. Portanto a neuroimagem não prova que a dislexia existe (MOYSÉS, 2010, p. 18).

Não se trata de afirmar, levianamente, que não existam doenças que, ao interferirem nas atividades habituais de um indivíduo, atinjam também as atividades intelectuais, bem como a aprendizagem. Tampouco se nega o número crescente de sujeitos que, a despeito de anos de escolaridade, não alcançam um grau de letramento que os possibilite vivenciar efetivamente práticas sociais e profissionais que envolvam a cultura escrita. O que se questiona, neste artigo, é a origem biológica desta última problemática.

Reiteramos o enfrentamento contra o que Moysés (2001) denomina de o mito do fracasso escolar, a partir do qual se dissemina a ideia de que questões orgânicas são responsáveis, pelo menos em parte, pelo fracasso escolar. Segundo a autora, os problemas de saúde dos escolares superpõem-se ao perfil de morbidade da população em geral: questões de origem basicamente social. Contudo, o mito explicitado é o de que o sujeito escolar brasileiro venha a sofrer de doenças que, todavia, não prejudicam suas atividades extraescolares. São crianças, "normais até entrarem em uma escola excludente, são tomadas como incapazes de aprender, reféns de doenças inexistentes, de fracassos que não são seus, sendo por fim aprisionadas em instituições invisíveis" (MOYSÉS, 2001, p. 36). Trata-se de uma exclusão silenciosa, ocultada pelos modos de significação e de produção de sentidos presentes nos discursos médicos e pedagógicos sobre o desenvolvimento e a subjetividade humana. 


\section{Estudos histórico-culturais e a superação da noção de sujeito do fracasso escolar}

Conforme sinalizado, a hipótese de um determinismo biológico para os problemas escolares é sustentada por paradigmas positivistas naturalistas que vêm influenciando os conceitos subjacentes à aprendizagem da língua escrita. A partir de tais paradigmas, o que se observa é a transferência do campo das investigações da linguagem, enquanto fenômeno simbólico, individual, para o campo das ciências naturais, biomédicas, tratando-a como fenômeno estritamente biológico, estável e universal. Esses estudos, ao pressuporem a linguagem como um sistema biológico e uma universalidade em sua aquisição e desenvolvimento, induziram à ideia equivocada de que modos de leitura e escrita que não coincidem com escalas normativas seriam decorrentes de um problema intrínseco ao sujeito uma vez que tal desenvolvimento seria determinado biologicamente.

Contrariamente, os estudos histórico-culturais apontam que a mente humana e a produção mental - enfim, a linguagem - apresentam uma natureza diversa e não podem se confundir com o aspecto neurofisiológico da mente, ou seja, com o funcionamento do cérebro - um fenômeno físico natural. A mente e a linguagem, enquanto fenômenos simbólicos, apesar de se constituírem a partir de uma condição humana, se organizam sócio culturalmente, variando, portanto, de pessoa a pessoa. Estudos como de Vygotsky (2007) e Bruner (1986) corroboram tal entendimento ao sinalizarem para as implicações do meio cultural no funcionamento da mente e na constituição da linguagem, permitindo a compreensão de que diferentes sujeitos interagem e conceituam a escrita de modos diversos, uma vez que apresentam organização e operação mentais singulares, que, por sua vez, implicam formas diversas de interação com o mundo, com o outro e com a cultura escrita.

Todavia, os estudos de natureza naturalística desenvolvimentista não foram verificar tal diversidade ao predeterminarem o modo de escrita e leitura padrão, bem como suas etapas e tempo de desenvolvimento. Isso porque o corpo teórico desenvolvido por essas teorias tem como sujeito de pesquisa o sujeito cartesiano - idealizado, atemporal e universal - que ajuíza o mundo, estrutura e faz uso da linguagem a partir de parâmetros lógico-formais. Tal sujeito em nada pode ser identificado com os sujeitos reais, alunos das escolas públicas brasileiras especialmente aqueles que têm sido referidos como os sujeitos do fracasso escolar.

Sobre esse aspecto, é preciso considerar que em ciências humanas, a pesquisa empírica observacional não opera sobre dados materiais, porém, sobre realidades intuídas pelo pesquisador a partir do observado (IANNI, 2004). Senna (2012) complementa que o ponto de partida das hipóteses em ciências humanas são valores ordenados em determinados paradigmas 
e não estados materiais definitivamente comprováveis na realidade de mundo. O problema resulta do fato de que a construção fenomenológica do objeto a ser investigado, ou seja, a linguagem, não se submete ao processo de observação, já que tal fenômeno consiste em matéria simbólica, portanto, existente no mundo das ideias e das representações mentais.

Isto implica que estar em investigação de campo na área da linguagem, não significa necessariamente estar diante de sujeitos ou alunos reais, uma vez que os paradigmas conceituais do pesquisador continuam prevalecendo sobre a observação e sobre toda a experimentação que se produza. Mais especificamente, na definição do que seja normal ou patológico em termos de linguagem escrita prevalece sempre o julgamento do pesquisador, influenciado por paradigmas conceituais. O que leva a um pesquisador ou um professor a caracterizar o erro em uma dada forma escrita ou modo de leitura que se apresentem fora dos padrões da norma canônica da escrita alfabética e seus usos culturais é, acima de tudo, a incapacidade de analisá-los (ou assimilá-los, nos termos da teoria de Piaget) a partir de seus fundamentos teóricos fundados no que vimos chamando aqui paradigmas positivistas. Não lhes sendo possível explicar tais desvios como fenômenos derivados de fatores plenamente justificáveis, resta-lhes explicá-los tão somente como desvios patológicos, frutos de anormalidades. O olhar para estes fatos do processo de alfabetização a partir do paradigma histórico-cultural proporciona a oportunidade de os apreciar como fenômenos explanáveis, plenamente previsíveis e justificáveis com base em fatos determinantes. Enfim, muda-se a lente e a realidade se transforma.

Ancorados na perspectiva histórico-cultural, é possível afirmar que a diversidade de escritas tem tal proporção que não pode ser tomada como desvios ou sintomas de patologias neurofisiológicas. Essa diversidade é decorrente da pluralidade histórico-cultural que constitui não só os sujeitos escolares, mas a sociedade brasileira. A consideração de tal pluralidade implica aventar uma teoria sobre a mente que se contraponha à suposta neutralidade sociocultural de teorias de cunho naturalista universalizante.

Machado (2013) discute uma teoria sobre a mente que destaca os diferentes modos como os sujeitos de culturas diversas estruturam e fazem uso da escrita e da fala. Segundo a autora, sujeitos pertencentes a uma cultura com alto nível de letramento, em que a escrita está presente em seu dia a dia como fator ordinário e necessário, desenvolvem um modo de pensamento científico e podem facilmente formular escritas que se aproximem da escrita padrão. Isso porque para produzir um texto escrito formal o sujeito precisa dispor de um modo de organização mental que lhe permita operar sobre dados logicamente ordenados causal e temporalmente, planejados previamente e não contextualizados em concreto. Ou seja, a escrita padrão está associada a um modo de pensar científico. 
Por outro lado, segundo Machado (2013), sujeitos pertencentes a culturas em que a oralidade prevalece sobre a cultura escrita, uma vez que lhes são imputados um acesso restrito aos bens culturais construídos pela humanidade, tendem a privilegiar um modo de pensamento narrativo e podem produzir modos de escrita singulares, com símbolos gráficos que se apresentam de forma incidental e casual, com uma organização morfossintática com marcas de sua oralidade, revelando baixo nível de planejamento e de controle de variáveis. Quanto mais periférica a condição do sujeito social em relação ao mundo cartesiano, mais distante estará sua escrita da norma padrão.

No entanto, as manifestações de escritas que diferem da norma padrão não podem ser interpretadas como sinais ou sintomas de uma patologia intrínseca ao sujeito, ao contrário, devem ser vistas como indicativas da diversidade de formas de se apropriar, de elaborar e representar a escrita. Nesse sentido, é preciso despatologizar os processos de aprendizagem humana, compreendendo-a como fenômeno complexo que envolve uma multiplicidade de fatores, que jamais pode ser reduzido a uma questão de natureza simplesmente biológica.

Sob tal perspectiva, também se faz necessário considerar que a aprendizagem da língua escrita envolve muito mais do que simplesmente sua conceituação e uso nos mais variados contextos de produção, pois se trata da própria constituição da identidade do sujeito como um sujeito da cultura escrita. Esse processo constitutivo se modifica constantemente, em função da história de interação do sujeito com a escrita e com os adultos que mediam tal processo, de modo que a interdiscursividade é questão sine qua non.

\section{A interdiscursividade como via para a produção de sentidos na aprendizagem escolar}

$\mathrm{Na}$ fronteira entre os processos de representação mental que nos garantem percursos únicos de aprendizagem e o modelo alfabético do sistema de escrita convencional está a experiência de formação escolar.

O tempo, o espaço e o que se vive na escola se explica a partir de bases culturais, científicas e históricas tecidas há séculos, mas sempre sujeitas a ressignificações que as validem na contemporaneidade. Desta forma, os processos formais de aprendizagem escolar se redefinem a todo momento porque se explicam contextualmente, como em todos os setores da vida: as relações familiares, profissionais, comerciais e as de gênero, entre tantas outras. Tudo se explica na complexidade e no emaranhado de muitas formas de se fazer presença e voz no mundo. 
No que tange à elaboração do conhecimento formalizado e selecionado pela escola, isto não se dá de forma diferente ou alheia aos modos contextuais de leitura do mundo. Ao contrário, à escola vem cabendo o desafio de promover o trânsito entre culturas ainda que tenham suas origens em princípios diferenciados.

É deste lugar que os estudos histórico-culturais motivam caminhos dialógicos, interculturais e interdiscursivos que priorizam práticas pedagógicas nas quais aprender com a escola se torna mais significativo do que a limitação de aprendizagens de qualquer conteúdo ou habilidade isoladamente. Aprender com representa aqui significação de experiências porque há interação, há conversa com o objeto da aprendizagem, há mediação entre culturas, já que é o diálogo com a vida e com o outro que pode fazer o objeto valer a pena e, assim, ser atribuído de sentido.

É exatamente pela urgência de inclusão dos sujeitos comumente tipificados como os de fracasso escolar que se busca analisar as práticas de ensino a partir dos contextos de mundo e de vida destes mesmos sujeitos. Recorre-se, então, à Teoria da Enunciação, bem como à Análise do Discurso, para que se possa pensar princípios coerentes no desenvolvimento de processos escolares mais inclusivos. Smolka (1999), ao tratar a alfabetização a partir da interação e da interlocução, justifica a eleição por estas duas teorias na consideração das questões pedagógicas.

Primeiro, porque, para mim, a alfabetização implica leitura e escritura que vejo como momentos discursivos. Segundo, porque o próprio processo de aquisição também vai se dando numa sucessão de momentos discursivos, de interlocução, de interação (SMOLKA, 1999, p. 29, grifos do autor).

Só se chega a este entrelugar a partir da consideração de estudos interdisciplinares que assumam os sujeitos da aprendizagem escolar para além de categorias determinadas biologicamente, psicologicamente ou neurofisiologicamente. Considera-se aqui, portanto, a dimensão discursiva que, embora se dê como experiência individual, é sempre permeada pela experiência discursiva também dos outros, em processos de interação e interlocução. Bakhtin (2016, p. 54) afirma que "a experiência discursiva individual de qualquer pessoa se forma e se desenvolve em uma interação constante e contínua com os enunciados individuais dos outros”.

É possível afirmar, portanto, que os sentidos do aprender, diretamente relacionados às experiências sociais, se constroem no dia a dia das escolas (mas não somente nelas), nas lógicas pessoais que são colocadas em jogo todas as vezes que os sujeitos se veem desafiados a pensar, a compartilhar suas hipóteses, a refutar outras, a explicar como chegou a determinada resposta 
e, igualmente, a escutar sobre como foi que o outro pensou, que hipóteses o outro elaborou, como o outro interage com este mesmo objeto do aprender.

Os sentidos do aprender e do não-aprender, portanto, são construções de toda a vida e não algo que possa ser ensinado. Não são prontos, não são únicos, pois se redefinem a cada nova leitura de mundo, a cada nova experiência intercultural e são, também, influenciados pelas tradições escolares e científicas - estas também passíveis de reconceptualização o tempo todo.

A interdiscursividade é, portanto, um princípio teórico-pedagógico que atende a demanda por sujeitos integrados, em plena atividade cognitiva e social, o tempo todo. As funções psicológicas superiores, conforme se elucida em Vygotsky (2007) são explicadas por conjunturas sociais e motivam formas específicas de organização do pensamento porque possibilitam que signos sejam não apenas utilizados, mas criados e, logo, não se manifestam alheios aos contextos de mundo. E mais do que isso, se conectam aos processos de significação elaborados pelos outros - parceiros nos processos de aprender -, o que justifica que, neste artigo, os processos discursivos se percebam validados se afeitos aos outros e, por isso, se fazem interdiscursivos.

As representações linguísticas dos sujeitos escolares são elaborações que passam pelas relações sociais e que estão fundamentalmente conexas à função constitutiva da linguagem e sua relação com o pensamento humano. Da mesma forma, a produção acadêmica, materializada nas leituras e escritas nas mais diferentes áreas do conhecimento escolar, tentam responder questões do cotidiano, do corpo e da vida. O que se pretende destacar aqui é que o corpo que estuda, que aprende, que elabora conceitos e que dá sentido a tudo isso, experiencia leituras de mundo para além do que realiza na escola.

Tais considerações são elencadas neste artigo porque a vida não se explica em fatores isolados e tecnicamente explicados apenas pelas áreas da Educação ou as da Saúde, assim como aquilo que se vive na escola também não permite simplificações. Assim, todo e qualquer agente mediador da aprendizagem escolar, na intenção de que a escola seja instrumento de inclusão, poderá buscar princípios de atuação que se aproximem dos sentidos destes dois pilares, sem os quais não há aprendizagem: o sujeito, com toda a sua cultura e marcas sociais; a escola como via de interação com a cultura científica contemporânea - ambos com fins de inclusão social.

Em uma análise filosófica que se propõe a pensar o texto (oral ou escrito) como uma realidade imediata e o lugar do mesmo nas ciências humanas, Bakhtin (2016) apresenta a atitude humana como um texto em potencial, podendo ser compreendida apenas se em contexto dialógico da própria época. 
As ciências humanas são as ciências do homem em sua especificidade e não de uma coisa muda ou um fenômeno natural. O homem em sua especificidade humana sempre exprime a si mesmo (fala), isto é, cria texto (ainda que potencial). Onde o homem é estudado fora do texto e independente deste já não se trata de ciências humanas (mas de anatomia e fisiologia do homem etc.) (BAKHTIN, 2016, p. 77).

A tradição científica escolar por muitos anos fundamentou suas práticas em métodos de ensino arraigados em teorias pré-determinantes da aprendizagem que, a partir de um modelo de sujeito, elegem comportamentos de aprendizagem para cada uma de suas etapas, como habilidades que evoluem a cada novo desafio. Ocorre, entretanto, que toda metodologia prémoldada em fases evolutivas se pauta em um determinado perfil de sujeito. Conforme discutido nas seções anteriores, esses métodos acabam por reforçar a noção de homogeneidade dos modos de aprender em detrimento das noções de diversidade e de representação individual de mundo, ambas inerentes à espécie humana numa perspectiva histórico-cultural.

Daí o caráter pedagógico da interdiscursividade para a produção de sentidos na aprendizagem: a opção por práticas de ensino voltadas para a elaboração de processos múltiplos de leituras de mundo e não apenas de apropriação de conteúdos produzidos sob bases deterministas e não sujeitas a críticas ou questionamentos. Para serem múltiplos, os processos de leitura de mundo pressupõem a relação entre discursos, o que justifica a escola e seu papel de ampliação das experiências sociais.

O percurso histórico dos métodos de ensino da leitura, desde os motivados pelos modos de produção industrial - que se refletiam em práticas de leitura de repetição e memorização -, passando pelos métodos motivados cientificamente e respaldados nos estudos da psicologia da aprendizagem ou nos estudos da linguística estruturalista, até práticas mais heurísticas desenvolvidas a partir da Psicogênese da Língua Escrita (FERREIRO; TEBEROSKY, 1985), revela sempre uma convergência entre as noções de mente, de sujeito, de ensino e de aprendizagem. Tais noções são evidenciadas também quando se analisa o contexto histórico e social no qual cada prática se valida em legitimidade e no qual a produção de ciência atende aos princípios dominantes.

Desde a década de 1980, portanto, são investidos esforços no sentido de que as políticas públicas nacionais de formação de leitores e escritores assumam as questões da discursividade como forma de aproximar as camadas sociais menos privilegiadas da sociedade às bases da cultura acadêmica e científica. Os esforços, desde então, se materializam na Lei de Diretrizes e Bases 9394/96 (BRASIL, 1996), nos Parâmetros Curriculares Nacionais (BRASIL, 1997), nas Diretrizes Curriculares Nacionais (BRASIL, 2013), mas se confundem na Base Nacional 
Comum Curricular (BRASIL, 2018), ao congregar princípios teóricos contraditórios, já superados e refutados pelos estudos da área, em diversas partes de seu documento.

Cabe às comunidades acadêmica e escolar, portanto, a produção científica que destaque o papel da escola como o espaço dos diferentes modos de aprender e da congregação de culturas que produzem discursos e sentidos variáveis na elaboração da leitura e da escrita. Estes discursos se entrecruzam porque servem a sujeitos integrados ao mundo e daí a interdiscursividade como via que se manifesta de maneiras múltiplas nas práticas de ensino, porque se faz sempre inédita, autoral e a se construir. Os discursos não são previsíveis ou controláveis porque se desenham contextualmente. Deste modo, a interação entre estes discursos se faz com intencionalidade pedagógica, mas não através da eleição de um método, já que esta noção pressupõe a idealização de um modelo de sujeito escolar.

A realidade brasileira é desigual em vários aspectos, sendo a diversidade, portanto, o princípio e o esteio para que as questões da aprendizagem sejam estudadas sempre contextualmente. Há uma dimensão ética envolvida quando se afirma sobre o fracasso ou o sucesso de aprendizagem de um sujeito escolar, pois esta análise vem sempre acompanhada de um parâmetro, de um valor e de um determinado lugar de fala.

\section{Considerações finais}

As noções de fracasso, de aprendizagem e de sujeito construídas e assumidas por cada agente de mediação escolar delineiam inclinações para práticas de ensino diferenciadas. Assim, quando se assume que tais noções sejam explicadas por princípios generalistas que elegem modelos de sujeitos e de modos de aprender, é comum a tendência por práticas de ensino reprodutoras de fragmentos de realidades fixas, absolutas, elaboradas a priori e fora de contextos socialmente relevantes.

Ao contrário, quando se assume a diversidade como princípio essencialmente humano que confere modos ímpares de interação com as realidades, a noção de fracasso do sujeito escolar não se aplica porque o ponto de chegada não é definido temporalmente. A aprendizagem se explica no caminho, no percurso, nas hipóteses, nas dúvidas e, principalmente, nas trocas sociais motivadas por discursos que se entrecruzam e, só por isso, produzem sentido.

Dito isto, assumindo a cultura escrita como registro de uma forma social de produção de linguagem, que se concretiza em determinada forma de interação com o mundo, a penalização do sujeito escolar como aquele que fracassa na aprendizagem é reflexo de uma cultura excludente. Decorrente desta cultura que se construiu a partir de bases científicas 
segregadoras, tem-se a escola apenada pelo status de que não consegue ensinar e o sujeito escolar pelo estigma de quem não consegue aprender. Este duplo conflito pode convergir em experiências de formação significantes através da disponibilidade para a construção de um ideário pedagógico que parta de situações socioculturais reais, motivando assim que a identidade pessoal prevaleça à categoria de sujeito escolar.

Com o intuito de fomentar reflexões que culminem em processos de aprendizagem repletos de sentidos, especialmente para as classes sociais vitimizadas pelos estigmas do fracasso, este artigo se encerra com as palavras de Colello (2012):

A compreensão do fracasso do ensino torna nítida a morosidade da transformação escolar, um processo sempre aquém das necessidades mais imediatas de nossos alunos. Na oscilação entre os avanços e os retrocessos, entre a ousadia e a resistência, ficam as sementes do saber e do fazer, sempre alimentadas pelas iniciativas, pelos esforços, pela reflexão e, certamente, pelos nossos sonhos (COLELLO, 2012, p. 99).

AGRADECIMENTOS: Este trabalho foi parcialmente financiado com recursos oriundos de fundos de pesquisa mantidos pelo programa Cientistas do Nosso Estado da Fundação FAPERJ (\#202629/2017) e pelo programa PROCIENCIA da Universidade do Estado do Rio de Janeiro.

\section{REFERÊNCIAS}

BAKHTIN, M. Os gêneros do discurso. São Paulo: Editora 34, 2016.

BRASIL. Decreto n. 9765, de 11 de abril de 2019. Institui a Política Nacional de Alfabetização. Brasília: MEC, 2019a. Disponível em:

https://legis.senado.leg.br/norma/30902116/publicacao/30905492. Acesso em: 20 mar. 2020.

BRASIL. Resolução n. 2, de 20 de dezembro de 2019. Define as Diretrizes Curriculares Nacionais para a Formação Inicial de Professores para a Educação Básica e institui a Base Nacional Comum para a Formação Inicial de Professores da Educação Básica (BNC Formação). Brasília: CNE, 2019b. Disponível em:

http://portal.mec.gov.br/docman/dezembro-2019-pdf/135951-rcp002-19/file. Acesso em: 20 mar. 2020.

BRASIL. Ministério da Educação. Secretaria de Educação Básica. Base Nacional Comum Curricular: educação é a base. Brasília: MEC/SEB, 2018.

BRASIL. Ministério da Educação. Diretrizes Curriculares Nacionais Gerais da Educação Básica. Brasília: MEC, SEB, DICEI, 2013.

BRASIL, Ministério da Educação. Parâmetros Curriculares Nacionais para o Ensino Fundamental. Brasília, MEC/SEF, 1997. 
BRASIL. Lei n. 9.394, de 20 de dezembro de 1996. Lei de Diretrizes e Bases da Educação Nacional. Diário Oficial da União: Seção 1, Brasília, DF, n. 248, p. 27833, 23 dez. 1996.

BRUNER, J. Actual minds, possible words. Cambridge: Harvard University Press, 1986.

COLELlo, S. M. G. A escola que (NÃO) ensina a escrever. São Paulo: Summus, 2012.

FERREIRO, E; TEBEROSKY, A. Psicogênese da língua escrita. Porto Alegre: Artes Médicas, 1985.

GARCIA, A. L. M. Fonoaudiologia e letramento. In: DAUDEN, A. T. B. C.; MORI-DE ANGELIS, C. C. Linguagem escrita: tendências e reflexões sobre o trabalho fonoaudiológico. São Paulo: Editora Pancast, 2004. p. 15-35.

HOBSBAWM, E. A era das revoluções. Rio de Janeiro: Paz e Terra, 1982.

IANNI, O. (Org.) Florestan fernandes: sociologia crítica e militante. São Paulo: Expressão Popular, 2004.

JAPIASSU, H. O sonho transdisciplinar: e as razões da filosofia. Rio de Janeiro: Imago, 2006.

MACHADO, M. L. C. A. A escrita alfabética, sua natureza e representação: contribuições à Fonoaudiologia aplicada à Educação. Orientador: Luiz Antônio Gomes Senna. 2013. 157 f. Tese (Doutorado em Educação) - Faculdade de Educação, Universidade do Estado do Rio de Janeiro, Rio de Janeiro, 2013

MACHADO, M. L. C. A. SIGNOR, R. C. F. Os transtornos funcionais específicos e a educação inclusiva. In: MARCHESAN, I. Q.; SILVA, H. J.; TOMÉ, M. C. Tratado das especialidades em fonoaudiologia. Sociedade Brasileira de Fonoaudiologia. 1. ed. São Paulo: Guanabara Koogan, 2014.

MOYSÉS, M. A. A. Dislexia existe? Questionamentos a partir de estudos científicos. In: BENEVENUTO, A. B.; ANGELUCCI, C. B.; BONOLENTA, L; MARTÃO, W. (Org.). Dislexia: subsídios para políticas públicas. Cadernos Temáticos Conselho Regional de Psicologia SP. São Paulo: CRP SP. 2010. v. 8. p. 11-23. Disponível em:

http://www.crpsp.org.br/portal/comunicação/cadernos_tematicos/8/frames/fr_dislexia. Acesso em: 20 mar. 2020.

MOYSÉS, M. A. A. A medicalização na educação infantil e no ensino fundamental e as políticas de formação docente. A medicalização do não-aprender-na-escola e a invenção da infância anormal. In: REUNIÃO ANUAL DA ANPED, 31., 2008, Caxambu. Anais [...] Caxambu: ANPEd, 2008. Disponível em:

http://31reuniao.anped.org.br/4sessao_especial/se $\% 20-\% 2012 \% 20$ -

\%20maria\%20aparecida\%20affonso\%20moyses\%20-\%20participante.pdf. Acesso em: 19 mar. 2020.

MOYSÉS, M. A. A. A institucionalização invisível: crianças que não-aprendem-na-escola. Campinas, SP: Mercado de Letras, 2001. 
MOYSÉS, M. A.; COLLARES, C. A. L. Medicalização o obscurantismo reinventado. In: COLLARES, C. A. L.; MOYSÉS, M. A.; RIBEIRO, M. C. (Org.). Novas capturas, antigos diagnósticos na era dos transtornos. São Paulo: Mercado de Letras, 2013. p. 41-65.

PATTO, M. H. S. A produção do fracasso escolar: histórias de submissão e rebeldia. 3. ed. São Paulo: Casa do Psicólogo, 2008.

SENNA, L. A. G. O campo acadêmico do letramento e da alfabetização no Brasil: estados e perspectivas da pesquisa em linguística aplicada. In: COLÓQUIO BRASILEIRO

EDUCAÇÃO NA SOCIEDADE CONTEMPORÂNEA, 3., 2012, Campina Grande. Anais [...]. Campina Grande: UFCG, 2012.

SMOLKA, A. L. B. A criança na fase inicial da escrita: a alfabetização como processo discursivo. São Paulo: Cortez; Campinas, SP: Editora da Universidade Estadual de Campinas, 1999.

VYGOTSKY, L. S. A formação social da mente: o desenvolvimento dos processos psicológicos superiores. 7. ed. São Paulo: Martins Fontes, 2007.

\section{Como referenciar este artigo}

MACHADO, M. L. C. A; LOPES, P. S. V. C; SENNA, L. A. G. Notas sobre fracasso e diversidade: os sentidos do aprender e do não aprender na escola. Revista Ibero-Americana de Estudos em Educação, Araraquara, v. 15, n. esp. 5, p. 2837-2854, dez. 2020. e-ISSN: 19825587. DOI: https://doi.org/10.21723/riaee.v15iesp5.14561

Submetido em: 10/01/2020

Revisões requeridas em: 25/05/2020

Aprovado em: 30/10/2020

Publicado em: 01/12/2020 